\title{
Recommendations For Faculty Development To Improve College Classroom Instruction
}

\author{
Mary Kennedy Minter, (Email: home1670@aol.com), Education Management Consultant
}

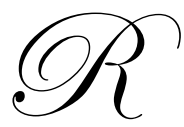

eflect on these teaching-related questions:

- What is your teaching pedagogy?

- $\quad$ Do you use the lecture format most of the time to present information to your students?

- $\quad$ Estimate the time per class period that you engage students in a meaningful discussion (not just a short question/answer process)?

- $\quad$ Do you regularly use the Power Point as a visual aid? If yes, what percent of your class time do you use the Power Point as a visual?

- $\quad$ Do you provide students with on-line copies of your lecture notes?

- What percent of your student testing relies on the use of objective or machine scored exams?

These are sample questions that can be asked faculty members at the beginning of group training sessions to determine faculty development needs and faculty interests in topics for in-service training.

The emphasis in this paper is on basic principles of pedagogy and communication in the classroom. An underlying need for faculty development emerges because the majority of college professors have not had training in "how to teach." Faculty are products of master and doctorate degree programs where the emphasis is on research and writing theses/dissertations, not teaching. Usually, only those professors who came to college teaching through the levels of elementary or high school teaching were required to have courses in pedagogy. The basic contention of this paper is that faculty development (in-service training and coaching) is needed to improve college classroom instruction, specifically related to classroom pedagogy and communication.

A crucial factor in the needs analysis stage of Faculty Development is the "readiness of the university/college" for such in-service training. For example, administration's financial support and commitment must be available in order for any such program to succeed. Also, there should be a faculty survey to determine the percentage of the professional staff who are interested in participating in the in-service offerings and what topics they think should be discussed.

There is growing interest in Faculty Development in the USA since many universities/colleges have established Centers for Teaching and Learning. This movement toward in-service faculty development has been encouraged mainly due to the increasing emphasis on accreditation agencies requiring assurance of learning measures. This is forcing institutions to assess "how faculty are teaching" and "what are the specific results or learning outcomes of classroom instruction."

The author's interest in faculty development began 20 years ago at the University of Michigan-Dearborn campus where she was director of a consortium for six local Detroit colleges. The consortium was established to produce faculty development materials (videotapes and manuals) for in-service training of faculty in the Detroit area. As the director for five years, the author marketed and conducted faculty development workshops nationwide at many universities and colleges. 


\section{PLANNING FOR FACULTY DEVELOPMENT}

The basic proposal in this paper is that in-service teacher training can benefit most higher education faculty and can improve classroom instruction.

Before discussing specifics regarding an entry-level approach to Faculty Instructional Development, a few basic operational definitions are necessary.

First, what do we mean by "classroom instruction." In education, the term "pedagogy" is often used. A common definition of pedagogy is "learning how to teach (i.e., methods for learning most often used in a classroom). The dictionary definition even refers to pedagogy as "the art or profession of teaching or preparation for training or instruction". The root word for pedagogy is from a Greek word meaning, 'to lead." Regardless of your area of subject matter expertise, we need to engage in the art of instruction and leadership. How successful are we?

Second, a classic education foundation for classroom instruction is based on Benjamin Bloom's Hierarchy of Cognitive Thinking (and learning). In his theory, which has been used in very pragmatic ways to structure classroom instruction, Bloom outlines the normal sequence of our cognitive learning: ${ }^{1}$

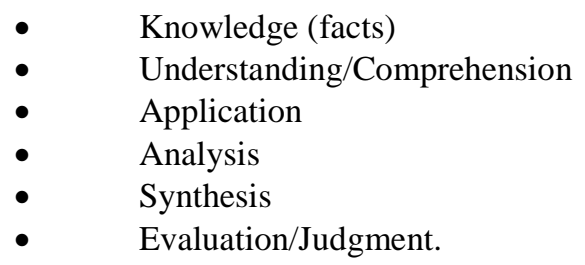

This hierarchical arrangement indicates that our thinking ranges from the simple to the complex, or from concrete to abstract (facts to synthesis and judgment). In actuality, we usually are processing elements from all levels of thinking at any given time. Each level of thinking can be related to levels of learning that our instructional methods aim at accomplishing. Listed below are sample methods of instruction that can stimulate each level of cognitive thinking and produce learning at that level.

- Knowing: Learn, and then recall, a set of specific commands that are used to format a computerized spreadsheet.

- Comprehending: Draw a diagram that demonstrates the order of executing specific commands for a spreadsheet.

- $\quad$ Applying: Use learned commands in setting up and executing the format of one's own spreadsheet data.

- Analyzing: Determine the underlying components of formatting a spreadsheet by examining and distinguishing the difference between "commands" and "functions" for keyboard operations.

- Synthesizing: Integrate a family of commands with a set of keyboard-entered functions in order to produce a new format of a spreadsheet.

- Evaluating: Assess the soundness and correctness of one's own spreadsheet results by testing it with raw data and known conclusions.

A basic objective of classroom instruction should be to engage students in all levels of thinking and learning through appropriate exercises that lead to this result. ${ }^{2}$

A faculty training exercise to demonstrate the practicality of Bloom's thinking levels is to ask faculty to construct a matrix to assess how they are addressing each level in their classroom instruction. For example, on one axis, we list the specific learning objectives of the course including basic information and special skills. On the other axis are listed the five levels of thinking/learning. Under each of these categories, faculty are asked to list what measures of assessment (and estimated percentage of classroom time) are devoted to each category. The results of this matrix exercise usually show that the majority of the time and assessments in classrooms are spent at 
the lowest levels of learning, i.e., knowledge transmission and comprehension. The learning levels of application, analysis, synthesis, and evaluation take second place when only multiple-choice exams are given and when only the lecture method of instructing is used.

Third, a crucial part of classroom instruction is communication, i.e., not just what subject is being taught, but "how one is delivering that information;" hence, there is a need for faculty to demonstrate competent communication skills. If part of the "art of pedagogy" is being a "leader," an effective leader, also, needs to be skilled in basic management skills. Effective communication is the foundation for an effective leader and classroom manager. According to one view of the leadership/management concept, "Although [a] distinction between leadership and management may have been appropriate in previous decades, that is no longer the case. Managers cannot be successful without being good leaders, and leaders cannot be successful without being good managers." $" 3$ This is the position that the author is taking when defining the classroom instructor as both a leader and a manager of learning. The process of learning is more than an "art;" teaching for all levels of learning involves all the skills of a manager in business and those skills have communication as a foundation.

An appropriate profile for the communication foundation is reference to a study conducted to determine characteristics of effective managers/leaders. The researchers interviewed 402 managers who were rated by their peers and superiors as most effective. From those interviews, 60 characteristics of effective managers were identified. Listed below are the 10 characteristics listed most often. Notice that all 10 are behavioral skills involving COMMUNICATION and all of these skills can be directly related to skills that faculty need for effective classroom instruction.

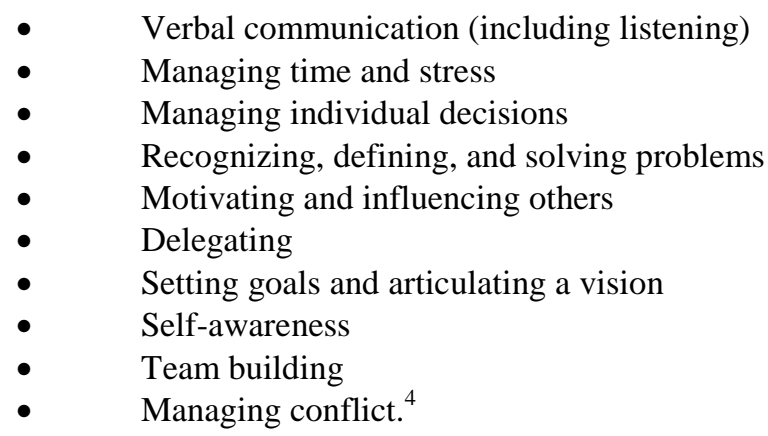

The contention is that the faculty member must be prepared to be an effective leader/manager and communicator in order to provide the best possible learning environment for the student (the consumer of the teaching product). The caveat, of course, is whether the student (consumer) will take full advantage of that which is offered in the best possible package.

\section{SPECIFIC EXAMPLES OF FACULTY DEVELOPMENT IN-SERVICE TOPICS}

Recommended starting points for in-service topics are:

- $\quad$ Establishing course goals and objectives

- $\quad$ The first day: making content and expectations clear (designing the syllabus)

- $\quad$ Planning the lesson (daily class planning)

- $\quad$ Planning instruction for higher levels of thought (the Bloom Hierarchy of thinking)

- $\quad$ Cultural Communication (including the need for clarity in English communication)

- $\quad$ Assessing Evaluation Methods (testing) and Assurance of Learning Measures

- Managing Group Discussion.

In the author's research, the topics above were the ones most often identified by departmental chairpersons based on observations of faculty teaching methods and by the faculty themselves, based on what they perceived 
would be helpful in-service topics for them and/or would be of interest to them. These topics encompass the basics of educational pedagogy.

A typical beginning discussion topic is often the course syllabus. Many college departments have established a standard format for syllabi that the faculty are required to use. However, there is usually room for each faculty to adapt the syllabus to a particular content and method of teaching. The most important factor for today's institutional emphasis on course assessments is to have specific learning objectives and assessments to demonstrate that students have accomplished those objectives. This is a good beginning topic for faculty inservice because the most appropriate and effective methods of instruction should be determined once the specific learning objectives have been identified.

One method of in-service pedagogy to avoid is using the straight "lecture." Since an objective is to provide samples and modeling of different methods of instructing, the in-service leaders should "practice what is being preached." Therefore, in presenting the advantages (and disadvantages) of other methods of instructing, we use as many methods as possible. For example, small group "brainstorming" is a good method to use to begin listing the different ways that learning objectives can be presented. Demonstrations by faculty who have found particular methods very effective in their classes are excellent ways for faculty to become involved and teach each other new approaches. Videotapes of exemplary faculty presentations can be provided followed by group critique and assessment. Case studies can be provided for small group analysis and recommendations. The proper use of various visual aids (e.g. Power Point) can be demonstrated. For example, especially important is a demonstration (and detailed in-service) on how to design and utilize an effective Power Point as a visual aid, not as a substitute for the lecture. These are just basic examples of how to approach pedagogy or the methods of instructing for faculty development.

What about the communication component of classroom pedagogy? Since we conduct our USA courses in English, we need to assess the clarity with which international faculty can orally communicate in English. Faculty for whom English is a second language often are challenged by accents that make it very difficult, if not impossible, for American students to understand what is being communicated. Perhaps this is a situation where an English version of lecture notes is practical and/or necessary. However, the better scenario is that English speaking training and practice should be provided, as needed, for the international faculty. Many universities (such as the University of Michigan) have implemented required assessments for faculty and required English training as a "bona fide" skill for continued employment.

In addition, faculty need to be able to establish good standards and criteria for assessing students' oral communication assignments within the classroom setting, for example, oral reports and group presentations. Not only is oral English communication a common need area, but also, the mechanics of written English. Ironically, this is often a basic need across the curriculum for native English speaking faculty as well as those for whom English is the second language. The key factor: if faculty are encouraged to supplement multiple-choice exams with written paper assessments, then they need to establish good standards and criteria for assessing those written assignments. How can the faculty member adequately assess students' writing without knowledge of the acceptable mechanics of the English language? Faculty are responsible for doing more than just grading content and authenticity of written papers; they also need to assess the appropriate style, technique, and mechanics of written communication, for example, those standards that students will be expected to demonstrate in the business world. How effective can student be in their writing if faculty are not prepared to competently assess the students' basic written English skills and mechanics?

\section{SELF-ASSESSMENTS AS A METHOD FOR IMPROVING INSTRUCTION}

A basic beginning point for Faculty Development for improving the learning environment is for faculty and students to assess themselves on their own preferences in the following three areas: 
- Learning styles

- $\quad$ Listening styles

- Communication styles/skills

In faculty development sessions, faculty can assess themselves in these areas so they will know how they compare with their students. Inventories for learning styles, listening preferences, and communication skills can easily be administered to students at various times in the semester; however, it is best to do so early so that the results of the surveys can be referenced throughout the semester.

\section{Learning Survey}

The author has used a learning survey in her classes for over 10 years and has found that most students perceive themselves as active learners (they learn best by experimentation or doing). The other styles of learning surveyed include:

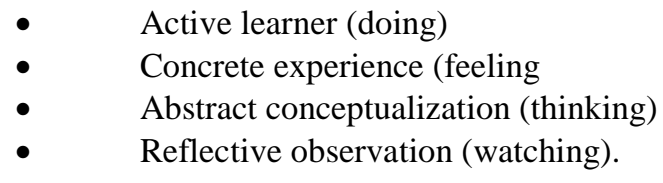

Although all of the above learning styles are probably used by the more flexible learners, the preference has been for "active learning." According to the D.A. Kolb inventory (which has been used for over 20 years in the USA), the closer an individual comes to the middle of the "grid" on the four learning styles, the more balanced (flexible) the individual's learning style is. ${ }^{5}$

Students should be encouraged to become more flexible in adapting to eclectic teaching styles which involves having them learn in many different ways that what they are used to (e.g., the lecture). The irony is that although students perceive themselves as "active learners," they are programmed in our classroom to expect a predominately lecture method of instruction. If most of the students in our classes really prefer to be actively involved (to be doing) and if we use the lecture method of instructing most of the time, are we really meeting their learning needs or preferences by placing them in a passive learning experience?

\section{Listening Survey}

A listening style inventory can be administered for students to assess how they perceive themselves as listeners. It is important for them to become sensitive to "how they listen" in order to improve their own listening, which is a crucial skill needed in a college learning environment and in any business situation that they will enter. The basic listening profile includes FOUR preferences:

\section{- $\quad$ People-oriented \\ - $\quad$ Action-oriented \\ - $\quad$ Content-oriented \\ - Time-oriented.}

The author has found that the majority of students perceive themselves as action-oriented listeners. This kind of listener is characterized as one who wants or expects a speaker to:
- $\quad$ Get to the point quickly
- Give clear feedback concerning expectations
- $\quad$ Concentrate on explaining the task at hand
- Help others focus on what is important
- $\quad$ Encourage others to be organized and concise 
The listener characteristics listed above are excellent criteria on which to assess the effectiveness of faculty teaching. It is no wonder that many "action-oriented" students tend to be impatient with rambling lectures and often interrupt the teacher with blunt questions. ${ }^{6}$

\section{Communication Style And Skills}

Communication style inventories can be administered depending on the type of course and time restraints. Before engaging faculty in communication self-assessment, it can be helpful to discuss perceptions of "style" in teaching. One paradigm of "style" was suggested by B. K. Zanger in a textbook for Sport Management. ${ }^{7}$ As she has described, "style" is a combination of knowledge, skill, and techniques with which an individual CREATES a "signature" (or style). Relating this definition of style to the "art of teaching," we can define style as a combination of:

- $\quad$ course content-faculty's knowledge of the subject being taught

- $\quad$ skill—the skills with which faculty execute the methods of teaching (lecture, discussion, case studies, demonstrations, student oral presentations, written assignments, assessments, etc.)

- techniques - kinds of visual aids used and individual personality traits exhibited by the faculty as the knowledge is communicated and delivered.

The manner in which a teacher COMBINES those elements-knowledge, skill, and techniques-will CREATE a "personal, one-of-a-kind" faculty STYLE. As faculty, we tend to develop our own style as we learn our "craft of teaching." We have only to look at other vocations to recognize "style" in performers. For example, we can usually recognize the voice style of famous singers such as Frank Sinatra, Ella Fitzgerald, Ray Charles, Louis Armstrong, Julia Andrews, or Bob Marley. A question to faculty is: Can you describe your "style of teaching," and are you comfortable and successful with that style? Perhaps, we all could do with more "coaching" in style to improve our ratings and results.

\section{Faculty Self-Assessment Based On In-Class Videotaping}

A very helpful in-service coaching method is to encourage faculty to arrange for themselves to be videotaped "in action" during their classroom presentations and interactions with students. The videotape helps the instructor analyze what went wrong and what improvements are needed. The beauty of the videotape selfassessment approach is that NO ONE else needs to see it. The weak points of instruction will usually be VERY EVIDENT, without anyone else pointing them out. For the very brave souls, the self-assessment videotaped can be shared with a trusted colleague whom we ask to critique it for us. This sharing can be used as part of the "Buddy System" that is described below.

For faculty development programs, the presenter can show a videotape of her/his classroom instruction for other faculty to comment on and critique. The tape can serve as an example that we all have aspects of our teaching which can be improved. The author has been able to improve her presentations and classroom instruction over the years by using this self-assessment method, but it is an on-going process for self-improvement.

Another benefit of videotaping a good sample of your classroom instruction (methods used, including facilitating student interaction) is that you can use a copy of that tape to include in your faculty development portfolio as part of your yearly faculty evaluation/assessment.

\section{Faculty In-Service Coaching (The "Buddy System")}

The idea of "coaching" brings us to another "method" of faculty development. Many universities or Centers for Teaching and Learning have established a peer coaching system, often referred to as a "Buddy System." The underlying approach to this in-service training is that we can "learn from each other," that is, faculty members can pair up and form a "buddy system." Each person will observe and comment on the other's teaching. It should be a voluntary and self-selected situation where faculty decide whom they feel comfortable with in sharing the 
usually "private domain" of the classroom. Criteria for assessing each other can be provided based on a faculty designed format of criteria for effective classroom instruction. The buddy system can be very beneficial to all faculty who participate.

\section{SUMMARY}

In summary of this brief overview of a Faculty Development approach, the main action steps have been:

1. Complete a thorough needs analysis for establishing a Faculty Development Plan, including:
a. What topics for in-services are of most interest and/or needed?
b. What is the level of administrative financial and incentive support?
c. Who will facilitate the in-service program?

2. Planning the Orientation for Faculty Development includes laying the groundwork through defining such terminology as: pedagogy, levels of learning, classroom communication including leadership and management.

3. Ideas for possible in-service training topics include:
a. creating the syllabus, learning objectives, daily lesson plans
b. methods of instruction for higher levels of thought and learning,
c. addressing cultural communication factors (including English as a second language)
d. criteria for both faculty and students regarding effective oral and written communication
e. self-assessments for faculty and students regarding preferred styles in learning, listening, and communicating
f. self-assessment by individual faculty through the use of videotaped classroom instruction
g. self-assessment through sharing with other faculty (e.g., the "Buddy System").

At the end of a major series of Faculty Development in-service workshops, faculty can be asked to complete a "Statement of Teaching Philosophy" based on what they have learned in the faculty development program. The author shares her own written teaching philosophy with them after they complete theirs, with the preface that the sample philosophy statement is not "new theory," but is based on principles that have been taught in education for many years. These principles have been reinforced by research studies during the 1980's and 1990's and form the bases for any approach to faculty development. Listed below is a brief list of "principles of good teaching practices" that the author tries to emulate.

1. Encourage contacts between student and teacher: Teaching should be an interactive model of communicating with the students rather than the use of a traditional lecture/listener model. Both the teacher/facilitator and learner can learn from each other.

2. Develop reciprocity and cooperation among students: Learning can be enhanced by being collaborative in nature and not isolated, i.e. sharing information with others and responding to others' ideas increases the ability to think critically and improve understanding.

3. Use active learning methods and techniques: "Learning is not a spectator sport." ${ }^{8}$ We tend to learn best by being involved. For example, we learn best what we teach others, so why not have students practice teaching each other?

4. Give feedback promptly: All of us need to have feedback about what we know and don't know. We need to learn how to monitor our own knowledge base, i.e., self-assessments. Faculty can learn much from students by using a classroom management technique of the "minute papers" or journals where students indicate what they have learned, what has been confusing, what they still want/need to know, etc.

5. Emphasize time on task: "Learning to use time well is critical for students and professional, alike." ${ }^{\text {Both }}$ faculty and students need to "learn how to learn" through better management of their time so that they can be more successful in their learning tasks.

6. Communicate high expectations: "Expecting students to perform well becomes a self-fulfilling prophecy when teachers and institutions hold high expectations of them and make extra efforts. "IO ${ }^{\text {These expectations }}$ need to be carefully outlined in the syllabus and discussed thoroughly at the beginning of the course. 
7. Respect diverse talents and ways of learning: A teacher/facilitator of student learning needs manage the classroom process so that diverse styles of learning can occur and the communication is effective no matter what cultural factors are present.

As teachers we are responsible for preparing students for their future workplace in society. According to a USA Department of Labor Commission report, basic skills needed for any kind of work is: "teaching others, working in groups, time and people management."11 All of these skills can be practiced in an "active learning" classroom environment that places the student in the middle of the learning model, with the instructor as a resource person, i.e., information-giver, facilitator, coach, and evaluator.

\section{FOOTNOTES}

${ }^{1}$ Bloom, Benjamin S., et.al. (1956). Taxonomy of Educational Objectives. New York:David McKay Company, Inc. ${ }^{2}$ Morshead, Richard W. (1986). College Teaching: The Classroom Discussion and Planning Instruction for Higher Levels of Thought, Monograph: Michigan Colleges' Consortium for Faculty Development. Dearborn, MI:

University of Michigan-Dearborn.

${ }^{3}$ Whetten, David A. \& Cameron, Kim S. (1998) (4 $4^{\text {th }}$ Ed.). Developing Management Skills. New York: AddisonWesley. 14.

${ }^{4}$ Ibid. 7

${ }^{5}$ Kolb, David A. (1985) Learning-Style Inventory. Boston, MA: McBer and Company.

${ }^{6}$ Watson, Kittie W. \& Barker, Larry L. (1995). San Francisco, CA: Jossey-Bass/Pfeiffer.

${ }^{7}$ Zanger, Beverly R. K. \& Parks, Janet B. (1990). Professional Style, Sport and Fitness Management, (Eds. Parks \& Zanger). Champaign, IL: Human Kinetics Books.

${ }^{8}$ Chickering, A. W. and Associates. (1981). The Modern American College. San Francisco:Jossey-Bass Publishers. ${ }^{9}$ Ibid.

${ }^{10}$ Ibid.

${ }^{11}$ Secretary's Commission on Achieving Necessary Skills. (1991). What Work Requires of Schools. Washington, DC: U.S. Department of Labor.

\section{OTHER REFERENCES}

1. McKeachie, Wilbert James \& Svinicke, Marilla. (2005). McKeachie's Teaching Tips: Strategies, Research and Theory for College and University Teachers. Boston: Houghton Mifflin

2. Bain, Ken. (2004). What the Best College Teachers Do. Cambridge: Harvard University Press.

3. Cooper, Pamela J. \& Simonds, Cheri J. (2003). ( $7^{\text {th }}$ Ed.) Communication for the Classroom Teacher.

Boston: Allyn and Bacon. 